\title{
Impact of Personal Epistemology, Heuristics and Personal Attributes on Investment Decisions
}

\author{
Sunitha Kumaran ${ }^{1}$ \\ ${ }^{1}$ Department of Finance, College of Business Administration, King Saud University, Riyadh, Kingdom of Saudi \\ Arabia \\ Correspondence: Dr. Sunitha Kumaran, Assistant Professor, Department of Finance, College of Business \\ Administration, King Saud University, Riyadh, Kingdom of Saudi Arabia. E-mail: sunithakravi@rediffmail.com
}

Received: March 7, 2013

Accepted: April 22, 2013

Online Published: June 24, 2013

doi:10.5430/ijfr.v4n3p62

URL: http://dx.doi.org/10.5430/ijfr.v4n3p62

\begin{abstract}
Investors who choose to invest or divest their funds abruptly contribute to the instability of the stock market. In such a volatile market when one investor chooses to invest in companies in spite of unstable prices, others decide not to invest. What individual indifference factors might predict opposing investment decisions such as these? Finance Literature proves that heuristics are significantly related to risky decision making and but there have been no studies to explore whether locus of control plays a role in behavioral finance. The present study has been undertaken to investigate whether locus of control predicts hot-come effect and its converse gambler's fallacy, when making personal investment decisions. The study has also analyzed investment experience as a possible determinant of hot-outcome or gambler's fallacy heuristics. The collective effect of an individual's locus of control and investment experience on investment decisions has been predicted using structural equation modeling. The present study has been done in the Kingdom of Saudi Arabia where 144 investors with prior investment experience and 124 new investors completed the Rotter's (1954) LOC and the adopted version of an Investment Survey Questionnaire. Results suggest that hot-outcome heuristic, trend length, trend valence and prior investment experience are factors that influence personal financial decision making. Results affirm that novice investors tend to utilize the hot-outcome heuristic regardless of the reference groups, while experienced investors from both reference groups apply gambler's fallacy heuristics to decide on investments.
\end{abstract}

Keywords: LOC, heuristics and decision making, investment bias, personal epistemology

\section{Introduction}

A behavioral finance perspective or school, which is made from psychological and financial integration, believes that psychology plays an important role in financial decision. Since cognitive errors and distortions impact investments' theories, therefore, they will also influence financial options.

Historians who have examined the behavior of financial markets over time have challenged the assumption of rationality that underlies much of the efficient market theory. They point to the frequency with which speculative bubbles have formed in financial markets, as investors buy into fads or get-rich-quick schemes, and the crashes with which these bubbles have ended. Thus they suggest that there is nothing to prevent the recurrence of this phenomenon in today's financial markets. In fact, the evidence on price patterns, in the short and long term, in different months and on different weekdays suggests that there is a lot about markets that we cannot explain with a rational investor model.

According to the prospect theory Kahneman and Tverskey (1979), psychological factors of investors will drive their actual decision-making process to deviate from rationality, which led to Simon's (1957) argument of bounded rationality. That's why investors often simplify their decision processes and are prone to behavioral heuristics that might cause systematic errors and lead to satisfactory investment choices, but does not maximize decisions. In recent decades, most empirical evidences generally view various behavioral biases as common cognitive illusions existing in decision making process among investors.

In this way, the purpose of this research is to explore the effect of personal epistemology (as measured by Rotter's 1954 Locus of Control Scale) on investment decisions. Based on the behavioral finance literature, personal epistemology and individual difference variables, such as the use of gamblers' fallacy and hot-outcome are expected 
to predict participants' responses in a hypothetical stock trading survey. In addition the research analyses the effect of winning versus losing streak of stock performance for various trend length and prior investment experience on investment strategies namely gambler's fallacy or the hot-outcome. In this way, we can better understand the antecedent of influence and the cause of investment biases.

\section{Literature Review}

In 1970, Fama has published an article entitled: "Efficient capital markets; overview of the theory and empirical studies" that in an efficient market the stock prices can reflex all the information in the financial market thoroughly. Traditional finance theory is based on the efficient market hypothesis (EMH). According to the theory, the general investors cannot earn abnormal returns by analyzing public information (Fama,1970). Until the later 1980s, some behavioral researchers found that the EMH cannot entirely explain the extraordinary phenomenon of the market and thought of the investment decision were not completely rational. When investors face uncertain conditions, they are likely to make different decisions or they may follow the relevant information to make profit from optimal investment decisions. Though the professional investors would obtain more sufficient information, their decisions are not all completely rational due to the existence of investment biases. These biases would consequently lead to return decline (Gaevey, Murphy, 2007), (Sehgal, Tripathi, 2009).

In 1979 Kahneman and Tverskey have developed the theory of prospect which focuses on the applications of psychological knowledge in financial and economic sciences. Based on the prospect theory, investors have an extreme tendency towards keeping securities which are in loss (due to not identifying loss) and vice versa, i.e. they tend to sell the securities which have profit (due to identifying profit). This bias is based on a mental accounting framework, which is called the disposition effect (Shefrin, Statman, 1985).

Kahneman and Tversky (1979) demonstrated the use of heuristic strategies in consumer stock trading. The factors Kahneman and Tversky examined were gambler's fallacy and the hot-outcome effect, trend lengths of investments, asymmetry among buying and selling decisions, and consumer preference when purchasing stocks. They concluded that the reason some investors continue to invest in losing stocks is the hope of a reversal in the trend in order to redeem their loss (demonstrating the use of gambler's fallacy heuristics).

In addition to disposition effect, there are other types of investment biases. For instance, if investors overestimate their own abilities of accurate forecast, they may be regarded as overconfident. Such investment bias would also lead to a return decrease on investment (Hirshleifer, 2001). Some studies indicate that males were more overconfident than females, and the return rate of males were causing a decrease of $2.65 \%$, while only causing a decrease of $1.72 \%$ for females (Barber, Odean, 2001).

Research indicated that investors' behavior will be affected by personality traits, interpretation of information, responses of sentiments, return and risk (Maital et al; 1986). There were many researches which used various dimensions to deal with the measurements of personality traits, Myers-Briggs Type Indicator (MBTI) by (Myers, McCaulley, 1985); Big five personality traits (Costa, McCrae, 1992).

Heuristics affects an individual's decision -making under ambiguity whether this decision is related to gambling, betting on sports, or personal finances. Wood (1992) explains these heuristics by comparing the use of heuristics when betting on sports versus when gambling or investing in the stock market. Wood compares the contributory explanations given by both coaches and financial analysts who seem to mirror each other as adhering to the same heuristics in an attempt to predict or control the outcome of a sports game or the stock market.

Rotter's Locus of control scale (1954) examines generalized expectancies for internal versus external control of reinforcement (Rotter, 1960). Sundali and Croson (2006) hypothesized that LOC would be related to binary prediction strategies. Consistent with the results, Hart and Levin (2007) found that the hot-outcome heuristic is significantly correlated to simpler epistemic belief systems (i.e., external LOC) as use of the hot-outcome heuristic ('stay strategy) was found to a much greater extent in children perhaps because it may be a more simple decision-making strategy. On the other hand, use of the gambler's fallacy heuristic ("switch strategy) was typically found to a much greater extent in adults.

Shefrin and Statman (1985) predicted that experienced investors would adhere to the gambler's fallacy strategy while inexperienced investors would adhere to the hot-outcome strategy.

Amir and Ganzach (1998) shed light on different heuristics (i.e. Representativeness, Anchoring and Adjustment, leniency) while making investment decisions. These heuristics show significant influence over decision making and it causes market over-reaction and under-reaction as well. Intrinsic factors such as experience, regret and perceived control are related to the investor rather than to the operations of stocks. 
A recent study by Johnson, Tellis and Macinnis (2005) provided evidence of a relationship between gambler's fallacy and hot-outcome effect in behavioral finance. Use of the gambler's fallacy heuristic leads investors to predict that an ongoing trend will reverse. Conversely, use of the hot-outcome heuristic leads investors to predict that the unbroken trend will continue. The outcomes of the study were: a. once a stock becomes positive, an individual would be more likely to invest. However, as the positive trend continues, an individual is less likely to purchase the same stock (demonstrating the use of gambler's fallacy heuristics) b. once a stock becomes negative, an investor would be more likely to sell the stock. Nevertheless, as the negative trend continues, this propensity would decline as the trend length continued (also demonstrating the use of gambler's fallacy heuristics) and c. consumers in the "buy" condition (purchasing shares) tend to show a preference for purchasing winning stock over losing stock, while individuals in the "sell" condition tend to show a preference for selling losing stock over winning stock.

Carvajal, Little, Turner and Williams (2009) further explored whether there was a link between an individual's personal epistemology, such as LOC, and gambler's fallacy versus hot-outcome. They hypothesized that an individual's personal epistemology will guide his or her decision-making in a coin-toss prediction experiment. Dogmatism (an open-minded versus closed-minded belief system), Adherence (a dualistic, right/wrong belief system versus a relativistic belief system), and LOC (external vs. internal) were the measures of personal epistemology used in the study. The authors hypothesized that externally-referenced LOC increases the likelihood of using a hot-outcome heuristic in predicting binary outcomes. An individual with an external LOC has the belief that an external force, such as an authority figure, chance or a higher power determines the outcomes of life events. On the other hand, an individual with an internal LOC has the belief that life's outcomes are due to his or her own actions or abilities.

\section{Research Methodology}

\subsection{Research Model and Hypotheses Development}

According to Kahneman and Tversky (1979) the investors use heuristic strategies in stock trading. Considering the reviews, researches show that i) an investor's LOC (a measure of personal epistemology) would affect his/her heuristics which is in turn reflected in their investment decisions. Carvajal et al (2009) ii) investors make decisions based on the trend length and the valence of the stock investment Johnson et al (2005) and iii) prior investment experience is positively related to the use of the gambler's fallacy heuristic (Shefrin and Stateman, 1985).

Accordingly, the proposed research model is that individual's LOC, heuristics namely hot-outcome and gambler's fallacy, prior investment experience, trend length and valence of the investment affect their stock investment decisions. Thus given below are the hypotheses related to the research:

Hypothesis 1: Investor with External Locus of Control will adopt hot-outcome heuristics while making investment decisions.

Hypothesis 2: Investor with Internal Locus of Control will adopt gambler's heuristics while making investment decisions.

Hypothesis 3: A longer trend length of positive or negative earnings for a given stock will amplify an individual's propensity towards a "stay" (hot-outcome) or "switch" (gambler's fallacy) strategy.

Hypothesis 4: A shorter trend length of positive or negative earnings for a given stock will curtail an individual's dispositions towards a "stay" (hot-outcome) or "switch" (gambler's fallacy) strategy.

Hypothesis 5: Prior Investment experience will be positively related to use of the gambler's fallacy heuristics.

\subsection{Instrument Development and Data Collection}

Personal epistemology is defined as an individual's personal belief system derived from knowledge used to understand the world. There have been several measures of personal epistemology over the past several decades. Rotter's Locus of Control Scale (1954) was used as a measure of personal epistemology. To evaluate the effect of Locus of Control on the investment decisions, participants completed Rotter's LOC survey and an Investment survey. In order to address whether LOC is related to decisions regarding personal investment strategies, internal LOC versus external LOC was measured using Rotter's (1954) LOC scale. Rotter's LOC scale measures the extent to which individuals relate various outcomes of life events to external forces or internal forces.

The investment survey contains eight investment scenarios in which the trend length and valence (winning versus losing streak of stock performance) were manipulated. Winning and losing stock were counterbalanced with trend lengths of six months versus six days. Long trend lengths were defined as unchanged stock performance over a period of six months and short trend lengths were defined as unchanged stock performance over a period of six days. 
Personal investment strategies were coded as gambler's fallacy under one of the two following conditions: a) if the participant chose to continue his or her investment in the losing stock (ostensibly because it is "due" to become a winning stock) or b) if the participant chose to remove the investment in the winning stock (because it is "due" to reverse its winning streak). Strategies were coded as hot-outcome under one of the two following conditions: a) if the participant chose to continue the investment in the winning stock (because it is believed that the winning streak will continue) or b) if the participant chose to remove his or her investment from the losing stock (because it is believed that the losing streak will continue). Use of gambler's fallacy versus hot-come served as the dependent variable. Trend length (six days versus six months) and trend valence (positive earnings versus negative earnings) served as the within subjects independent variable. Prior investment experience served as a quasi independent variable. The preliminary instrument was reviewed and tested through a pilot study. The Cronbach's $\alpha$ of scales was acceptable with the minimum score being above 0.7 .

A total of 268 successful questionnaires were obtained. The sample includes 124 respondents with no prior investment experience and 144 respondents with investment experience ranging from $1-7$ years. Of the respondents, 93\% were males from an average age group of 32 years. The average of Cronbach's alpha for the investment questionnaire related to investment decisions is 0.783 .

\subsection{Data Analysis}

\subsubsection{Testing of Hypothesis}

Hypothesis 1: Investor with External Locus of Control would adopt hot-outcome heuristics while making investment decisions.

Hypothesis 2: Investor with Internal Locus of Control would adopt gambler's heuristics while making investment decisions.

Table 1. Investment trends among investors with external locus of control

\begin{tabular}{|c|c|c|}
\hline $\begin{array}{l}\text { NATURE } \\
\text { INVESTOR }\end{array}$ & Positive Long Trend Length & Negative Long Trend Length \\
\hline Novice & $76 \%$ & $27 \%$ \\
\hline Experienced & $80 \%$ & $74 \%$ \\
\hline & Positive Short Trend Length & Negative Short Trend Length \\
\hline Novice & $69 \%$ & $19 \%$ \\
\hline Experienced & $48 \%$ & $83 \%$ \\
\hline \multicolumn{3}{|c|}{$\begin{array}{l}\mathrm{N}=67 \text { for novice investors with an external locus of control. } \mathrm{N}=46 \text { for experienced investors with an } \\
\text { external locus of control. The Table represents the percentage of novice and expert investors who } \\
\text { chose to invest in a particular stock. Choosing to keep an investment in a losing stock and choosing to } \\
\text { remove an investment from a winning stock designates a gambler's fallacy response. Choosing to keep } \\
\text { an investment in a winning stock fund choosing to remove an investment from a losing stock } \\
\text { designates a hot-outcome effect. }\end{array}$} \\
\hline
\end{tabular}

Results of novice investors with an external LOC (Table 1) reveal that inexperienced participants prefer to invest in stock with positive valence over stock with negative valence suggesting the use of the hot-outcome heuristics. The opposite pattern is found among externally referenced experienced investors. This group also preferred to invest in stock with long term positive valence (suggesting the use of the hot-outcome strategy) but showed a change in strategy from hot-outcome to gambler's fallacy for stocks with negative valence.

Results of novice investors with an internal LOC (Table 2) show the same investment pattern as their externally -referenced counterparts. That is, inexperienced participants preferred to invest in stock with positive valence, regardless of trend length, showing the use of hot-outcome heuristic. However, under conditions of short trend length with negative valence, internally referenced novice investors changed their strategy from hot-outcome to gambler's fallacy. This reveals that majority of internally-referenced novice investors rely on the gambler's fallacy heuristics under conditions of negatively -valence short trend lengths. 
Table 2. Investment trends among investors with internal locus of control

\begin{tabular}{|c|c|c|}
\hline $\begin{array}{l}\text { NATURE } \\
\text { INVESTOR }\end{array}$ & Positive Long Trend Length & Negative Long Trend Length \\
\hline Novice & $65 \%$ & $36 \%$ \\
\hline Experienced & $27 \%$ & $73 \%$ \\
\hline Novice & $\begin{array}{l}\text { Positive Short Trend Length } \\
60 \%\end{array}$ & $\begin{array}{l}\text { Negative Short Trend Length } \\
65 \%\end{array}$ \\
\hline Experienced & $32 \%$ & $70 \%$ \\
\hline \multicolumn{3}{|c|}{$\begin{array}{l}\mathrm{N}=57 \text { for novice investors with an internal locus of control. } \mathrm{N}=98 \text { for experienced investors with an } \\
\text { internal locus of control. The Table represents the percentages of novice and expert investors who } \\
\text { chose to invest in a particular stock. Choosing to keep an investment in a losing stock and choosing to } \\
\text { remove an investment from a winning stock designates a gambler's fallacy response. Choosing to keep } \\
\text { an investment in a winning stock fund choosing to remove an investment from a losing stock } \\
\text { designates a hot-outcome effect. }\end{array}$} \\
\hline
\end{tabular}

Internally referenced experienced investors preferred to invest with negative valence stock regardless of trend length. This reveals overall greater use of gambler's fallacy heuristics among experienced investors.

The first hypothesis is confirmed for inexperienced investors. In accordance, externally referenced inexperienced preferred to invest in positive valence stocks regardless of trend length which proves the usage of hot-outcome heuristics. But experienced investors preferred to invest in stock with long term positive valence (suggesting the use of the hot-outcome strategy) but showed a change in strategy from hot-outcome to gambler's fallacy for stocks with negative valence.

The second hypothesis is confirmed for experienced investors. Internally referenced experienced investors preferred to invest with negative valence stock regardless of trend length. This reveals overall greater use of gambler's fallacy heuristics among experienced investors. But, the group preferred to invest in stock with positive valence, regardless of trend length, showing the use of hot-outcome heuristic.

Hypothesis 3: A longer trend length of positive or negative earnings for a given stock will amplify an individual's propensity towards a "stay" (hot-outcome) or "switch" (gambler's fallacy) strategy.

Hypothesis 4: A shorter trend length of positive or negative earnings for a given stock will curtail an individual's dispositions towards a "stay" (hot-outcome) or "switch" (gambler's fallacy) strategy.

Majority of the novice investors in either LOC groups show no amplification or curtailment of heuristics use when trend length changed from short or long as they choose invest in winning stocks in both the trends. But, externally referenced experienced investors prefer to invest in stock with long term positive valence (suggesting the use of the hot-outcome strategy) but showed a change in strategy from hot-outcome to gambler's fallacy for stocks with short negative valence. Similarly internally referenced experienced investors changed their strategy from hot to gamblers' with the change in trend length. Hence hypothesis 3, 4 is proved for experienced investors from both the reference groups and the same is disproved for novice investors.

Hypothesis 5: Prior Investment experience will be positively related to use of the gambler's fallacy heuristics.

Novice investors for both LOC groups did show a greater use of the hot-outcome heuristics than experienced investors. Experienced investors from both the groups prefer to stay in short negative valence stocks expecting a reverse in trend showing a greater use of gambler's fallacy heuristics.

\subsubsection{Model Analysis}

\subsubsection{Proposed Structured Equation Model}

The study uses SEM to simultaneously estimate and test how latent variables and their measurements are related. Based on previous literature, a hypothetical structure equation model is proposed and analyzed with the AMOS 5 Software package.

For the present study the effect of variables namely individuals LOC and investment experience on investment heuristics (gambler's fallacy or hot-outcome) has been analysed. The effect of other variables such as personal and demography factors will be analysed and presented in the subsequent research. Considering the influence of personal characteristics /internal variables on investors' investment decisions, one can conclude that personal characteristics 
influence the investment strategy (hot-outcome /gambler's fallacy) and the structural model for this relationship is showed in Figure 1.

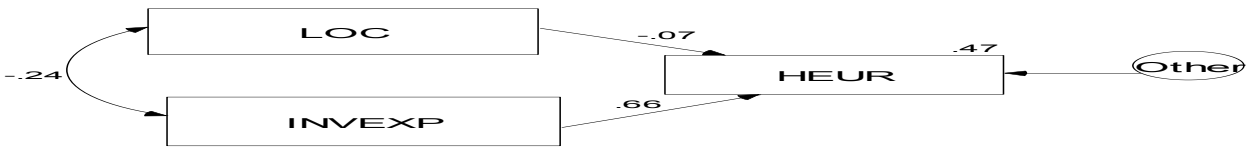

The tested model generated a meaningful relationship between the variables considered for analysis. The standardised regression weights shown in the model represents the amount of change in the dependent variable that is attributable to a single standard deviation unit's worth of change in the predictor variable. Negative correlation of -0.24 between LOC and Investment Experience shows that individuals with more trading experience ( $>2$ years) were identified as investors with Internal Locus of Control (scored less on the LOC scale) and vice-versa. A regression weight of -0.07 between LOC-- $\rightarrow$ HEUR shows a very small effect of Locus of Control on Investment Heuristics (hot-outcome / gambler's fallacy). The negative sign also supports the hypothesis that individuals with External Loc (high score in LOC scale) used hot-outcome heuristics in their investment decision (with low score in the investment scale). Similarly individuals with Internal LOC (low score in LOC scale) adopted gambler's fallacy heuristics while making investment decisions (with high score in the investment scale). Regression Estimate of 0.66 between INVEXP-- $\rightarrow$ HEUR shows a large effect of an individual's prior trading experience on his/her investment heuristics. If an investor had more prior trading experience ( $>2$ years) there is a greater chance that he would use gambler's-fallacy heuristics while making investment decision. On the other hand, investors with no or less trading experience tend to use hot-outcome heuristics for making investment decisions.

The Squared Multiple Correlation $\left(\mathrm{R}^{2}\right)$ of 0.47 represents the collective effect of Locus of Control and Investment Experience on the choice of investment heuristics (hot-outcome / gambler's fallacy ) made by an individual.

\subsubsection{Testing for Model Fit}

The goodness of fit of the proposed model is done based on fit indices produced by AMOS program. The fit indices used are: Chi-square test statistics, AGFI (adjusted goodness of fit index), GFI goodness of fit index), CFI (comparative fit index) and RMSEA (root mean square error of approximation).

Chi-square statistics test in Table 3 which is related to the size of relative sample will accept the fitness model if the amount of P-value in it is greater than 0.05 . The model is fit as the p-value $>0.05$ and hence we accept the hypothesis.

Table 3. Chi-square statistics

\begin{tabular}{llllll}
\hline Model & NPAR & CMIN & DF & P & CMIN/DF \\
\hline Default model & 5 & 2.207 & 1 & .137 & 2.207 \\
Saturated model & 6 & .000 & 0 & & \\
Independence model & 3 & 166.591 & 3 & .000 & 55.530
\end{tabular}

Goodness of Fit Index (GFI) and the Adjusted Goodness of Fit Index (AGFI) in Table 4. The values of these indices range from 0 (which indicates poor fit) to 1 (indicating perfect fit) (Schumacker and Lomax, 1996; Sobolewski and Doran, 1996). The GFI is a relative measure of how well the data fit the model (Sobolewski and Doran, 1996). Recommended values should be greater than 0.90 . The values for the GFI and AGFI in the default model in this study are 0.995 and 0.968 respectively indicating that there is model-data correspondence.

Table 4. Adjusted goodness of fit index \& goodness of fit index

\begin{tabular}{lllll}
\hline Model & RMR & GFI & AGFI & PGFI \\
\hline Default model & .366 & .995 & .968 & .166 \\
Saturated model & .000 & 1.000 & & \\
Independence model & 1.457 & .750 & .501 & .375 \\
\hline
\end{tabular}


The Comparative Fit Index (CFI) is an incremental fit index in Table 5, which indicates the proportion of the improvement of the overall fit of the final model relative to the independence (null) model (Kline, 1998 and Neilands, 2000). Recommended values are those greater than 0.90 . The CFI value for the final model in this study is 0.993 , which indicates that the relative overall fit of the model is 99 per cent better than the independence model estimated with the same sample data.

Table 5. Comparative fit index

\begin{tabular}{|c|c|c|c|c|c|}
\hline Model & $\begin{array}{l}\text { NFI } \\
\text { Delta1 }\end{array}$ & $\begin{array}{l}\text { RFI } \\
\text { rho1 }\end{array}$ & $\begin{array}{l}\text { IFI } \\
\text { Delta2 } \\
\end{array}$ & $\begin{array}{l}\text { TLI } \\
\text { rho2 }\end{array}$ & CFI \\
\hline Default model & .987 & .960 & .993 & .978 & .993 \\
\hline Saturated model & 1.000 & & 1.000 & & 1.000 \\
\hline Independence model & .000 & .000 & .000 & .000 & .000 \\
\hline
\end{tabular}

The Root Mean Square Error of Approximation (RMSEA) in Table 6, with its lower and upper confidence interval boundaries, is another very valuable fit index. The recommended values for this fit statistic are those below 0.06 (Schumacker and Lomax, 1996; Neilands, 2000). The value for the final model is 0.061 , which indicates a good model fit.

Table 6. Root mean square error of approximation

\begin{tabular}{lllll}
\hline Model & RMSEA & LO 90 & HI 90 & PCLOSE \\
\hline Default model & .061 & .000 & .192 & .263 \\
Independence model & .452 & .395 & .512 & .000 \\
\hline
\end{tabular}

\section{Contributions and Discussions}

Financial economists are increasingly coming to believe that the study of psychology and other social sciences can shed considerable light on the unpredictable and erratic nature of human behavior, and by extension, challenge the prevailing paradigm of efficiency of financial markets, as well as explain stock market anomalies, market bubbles, and crashes. Researchers now believe that these human flaws are consistent, predictable, and can be exploited for profit. The present study aims to contribute to the burgeoning interest in behavioral finance and growing body of research questioning the impact of individual and crowd psychology on decision-making in financial markets. The outcome of the paper would enable the recognition of human biases and accompanying irrationality warrants greater investigation so as not to repeat the mistakes of the past. The paper has explored whether there was a link between an individual's personal epistemology, such as Locus of Control, and the mechanism of stock market decision-making (using gambler's fallacy versus hot-outcome). The primary outcome of the paper, has confirmed that an individual's personal epistemology does have an effect on the investment decisions. Externally Referenced investors used hot-outcome heuristics, whereas internally referenced investors adopted gambler's fallacy heuristics while making stock purchases. The second outcome was that inexperienced investors depended on hot-outcome heuristics while experienced investors used gambler's fallacy heuristics to make stock purchase decisions. Experienced investors with external and internal reference choose to "switch" from positive valence stocks and "hold" investment in negative valence stocks as they expected a trend reversal to occur shortly. This signals the use of gambler's fallacy heuristics by experienced investors from either reference groups. Thus trade Experience of the investors was found to have a major effect on making stock investment decisions.

The third finding was that novice investors were not sensitive to a long or short trend length of a stock with positive or negative earnings, as they continued to stay with winning stocks i.e. they adopted hot-outcome heuristics. But experienced investors where sensitive to long or short trend of positive or negative valence of stock as they choose to invest in short negative valence stocks expecting a trend reversal shortly, showing the use of gambler's fallacy heuristics.

To navigate through an increasingly complex world, we utilize heuristics (hot-outcome/gambler's fallacy) in the process of decision making. Unfortunately, in the world of finance, too often heuristics does not help and it results in poor investment decisions. Heuristics, as a rule of thumb, make decision-making easier. But they can sometimes lead to biases, especially when things change. These can lead to suboptimal investment decisions.

Proponents of behavioral finance contend that heuristic-driven bias and framing effects cause market prices to deviate from fundamental values. It is argued that because these biases are an inherent part of all of our decision-making processes, they can systematically distort market behavior. In particular, the biases may result in i) Over or under reaction to price changes or news (depending on the bias) ii) Extrapolation of past trends into the future iii) Lack of attention to the fundamentals underlying a stock iv) Undue focus on popular stocks. If such patterns exist, there may be scope for investors to exploit the resulting pricing anomalies to capture superior, risk-adjusted returns. Proponents of EMH, in fact, argue that smart money will exploit such anomalies and drive 
prices to their fundamental values. Other research, however, shows that rational investor trading is unable to completely offset the actions of irrational investors. Strategies that would be most beneficial to individual investor decision-making, at their core, require self-awareness and discipline. Specifically, investors can immunize themselves from these biases by adapting the following strategies: 1. Understanding biases 2.Quantifying investment criteria: 3. Diversifying: 4. Controlling one's investment environment: 5. Understanding that earning the market rate of return, or even slight underperformance, should not be anathema.

\section{Conclusion}

The extent of research in the field of behavioral finance has grown noticeably in the past decade. The field merges concepts from financial economics, psychology and sociology in an attempt to construct a more detailed model of human behavior in financial markets. Even as behavioral factors undoubtedly play a role in the decision-making processes of investors, they do not quash all the predictions of efficient market theory; they offer plausible explanations of financial markets which would otherwise be categorized as anomalous. The current state of research from the efficient market and behavioral perspectives therefore suggests that an inclusive and diverse approach in the choice of theoretical explanations of the behavior of financial markets will be the pragmatic response to the inconclusive results on either side of the debate. While, on the one hand, investors are not making large sums of money from market anomalies, not many people will disagree that the stock market bubble burst of in 2000 or 2008 is better explained by hubris and irrational exuberance grounded in behavioral finance than by the efficient markets theory. This research benefits individual investors the most as it seeks to create awareness of the various human biases and the costs they impose on their portfolios, and argues for voluntary detachment from the "emotion" inherent in investing.

\section{References}

Carvajal, M., Little, T., Turner, L., \& Williams. (2009). Does personal epistemology play a role in gambler's fallacy? Houston, TX.

Fama, Eugene. (1998). Market efficiency, long-term returns, and behavioral finance. Journal of Financial Economics, 49(3), 283-306. http://dx.doi.org/10.1016/S0304-405X(98)00026-9

Hart, S., \& Levin, I. (2007, November). Locus of Control: A factor in gambler's fallacy and hot-outcome effect. Annual Conference for the Society for Judgment and Decision Making.

Johnson, J., Tellis, G., \& Macinnis, D. (2005). Losers, Winners and Biased Trades. Journal of Consumer Research, 32, 324-329. http://dx.doi.org/10.1086/432241

Kahneman, D., \& Tversky, A. (1979). Prospect theory: An analysis of decision under risk. Econometrica, 47, 263-291. http://dx.doi.org/10.2307/1914185

Lintner, G. (1998). Behavioral Finance: Why Investors make bad decisions. The Planner, 7-8.

Martin, J., Silva, G., Newman, J., \& Thayer, J. (1993). An investigation into the structure of epistemological style. Personality and Individual Differences, 16, 617-629. http://dx.doi.org/10.1016/0191-8869(94)90189-9

Rotter, J. (1954). Generalized expectancies for internal versus external control of reinforcement, Social learning and clinical psychology. Englewood Cliffs, NJ: Prentice Hall, 466. http://dx.doi.org/10.1037/10788-000

Shefrin, H., \& Statman, M. (1985). The disposition to sell winners too early and ride losers too long, Theory and evidence. Journal of Finance, 40, 777-790. http://dx.doi.org/10.1111/j.1540-6261.1985.tb05002.x

Shefrin, Hersh. (2000). Beyond Greed and Fear: Understanding behavioral finance and the psychology of investing. Harvard Business School Press, Boston, USA.

Shefrin, Hersh. (2001). Behavioral Corporate Finance. Journal of Applied Corporate Finance, 14(3), 113-124. http://dx.doi.org/10.1111/j.1745-6622.2001.tb00443.x

Shiller, Robert J. (2003). From Efficient Markets theory to behavioral finance. Journal of Economic Perspectives, 17(1), 83-104. http://dx.doi.org/10.1257/089533003321164967

Sudhir Singh. (2012). Investor Irrationality and Self-Defeating Behavior: Insights from Behavioral Finance. The Journal of Global Business Management, 8, 116-122.

Tversky, A., \& Kahneman, D. (1974). Judgment under uncertainty: Heuristics and Biases. Science, 185, 1124-1131. http://dx.doi.org/10.1126/science.185.4157.1124

Wood, G. (1992). Predicting Outcomes: Sports and Stocks. Journal of Gambling Studies, 8, 201-216. http://dx.doi.org/10.1007/BF01014636 